\title{
Home ventilation
}

\author{
A.K. Simonds
}

Home ventilation. A.K. Simonds. C) ERS Journals Ltd 2003.

ABSTRACT: Home ventilation is a growth area. Rapid expansion during the 1990s was stimulated by the development of noninvasive ventilation (NIV) via a mask and the recognition that an increased number of patient groups can benefit. Although patients receiving NIV in the home outnumber those receiving invasive ventilation via tracheostomy, there is substantial variation in practice between European countries.

Evidence that individuals who develop ventilatory failure as a consequence of chest wall disease or stable neuromuscular disease such as old poliomyelitis benefit from nocturnal NIV is overwhelming. Patients with progressive neuromuscular disease such as Duchenne muscular dystrophy and amyotrophic lateral sclerosis can also derive prolongation of life, palliation of symptoms and an improvement in quality of life.

Home ventilation in chronic obstructive pulmonary disease (COPD) patients remains controversial. Multicentric randomised controlled trials of long-term oxygen therapy (LTOT) versus NIV plus LTOT in COPD have produced mixed results, although certain subgroups, e.g. those with recurrent infective exacerbations requiring short-term NIV, patients aged $>65$ yrs, and those with uncontrolled hypercapnia on LTOT or symptomatic nocturnal hypoventilation, may benefit.

At the other end of the age spectrum, children as young as a few months can be successfully treated with noninvasive ventilation. Most work on paediatric home ventilation centres on children with congenital neuromuscular disease. Pressure preset bilevel ventilators are now the dominant form of ventilator in adults and children. Discharge planning is vital for the home ventilator patient and a sensible risk management strategy should be in place.

Eur Respir J 2003; 22: Suppl. 47, 38s-46s.
Correspondence: A.K. Simonds Royal Brompton Hospital Sydney Street

London SW3 6NP

UK

Fax: 442073518911

E-mail: a.simonds@rbh.nthames.nhs.uk

Keywords: Chest wall disorders chronic obstructive pulmonary disease neuromuscular disease noninvasive ventilation respiratory failure

Received: March 182003

Accepted after revision: June 292003
Ventilation in the home can be delivered invasively via tracheostomy or noninvasively by either mask intermittent positive- or negative-pressure devices.

The 1980s and 1990s have seen a substantial rise in the number of home ventilator-dependent patients due to an increase in the number of patients surviving critical illness, technological advances and the impact of noninvasive ventilation (NIV). A relatively small proportion require ventilation continuously and most of these patients receive intermittent positive-pressure ventilation via tracheostomy (T-IPPV), although an increasing number use round-the-clock NIV. The greatest expansion has been in patients using NIV via a mask during sleep. The present article focuses predominantly on home positive-pressure NIV, but also contrasts this with T-IPPV and negative-pressure ventilation (NPV) where relevant.

\section{Demographics}

ADAMS et al. [1] found that NIV was responsible for $47 \%$ of the growth in the number of chronic ventilator-assisted individuals in Minnesota (USA) between 1992 and 1997. An awareness that NIV may alter the natural history of a condition and palliate symptoms has also led to the application of ventilatory support in situations in which it was hitherto felt inappropriate to provide such assistance (e.g. amyotrophic lateral sclerosis (ALS)/motor neurone disease
(MND)). This is in line with the shift in societal expectations for patients with chronic disorders [2].

In the Minnesota series, there was a $110 \%$ increase in the number of ventilator-dependent patients between 1986 and 1992 and a 42\% increase between 1992 and 1997 [1]. The 1998 report of the Association Nationale pour le Traitement A Domicile de 1'Insufficance Respiratoire chronique Observatory (the French national database) shows that the uptake of NIV increased almost exponentially from 1988, with 500 persons receiving NIV in $1990,3,000$ by 1996 and 4,500 in 1998 [3]. By contrast, 2,000 individuals were using tracheostomy ventilation in 1988; this figure had increased to 2,500 in 1996, but subsequently showed a falling trend to 2,000 patients using T-IPPV in 1998. The US survey found that $35 \%$ of patients were receiving ventilatory support for $<24 \mathrm{~h} \cdot \mathrm{day}^{-1}$, i.e. the majority were highly ventilator-dependent. This differs from results elsewhere, which suggest that the greater proportion of patients receiving home ventilation use only nocturnal or nocturnal plus part-time diurnal nasal intermittent positive-pressure ventilation (NIPPV). This discrepancy can be explained by the fact that the US study included only patients using ventilators with a back-up respiratory frequency, so that those using bilevel machines without a back-up frequency (spontaneous mode) at night were excluded.

The US study demonstrated that the age groups showing most increase in ventilatory dependence were $<11$ yrs and $>70$ yrs [1]. Obstructive lung disease was the main indication for ventilatory support in the older patients, and the French 
data also show that the rate of uptake of home ventilation is increasing more rapidly in obstructive than in restrictive conditions. Not surprisingly, in view of the younger age of recipients and chronicity of the conditions, the neuromuscular group were ventilated for longer periods ( $>5 \mathrm{yrs}$ ) in the home.

Preliminary results from a European Commission-funded census show wide variation in practice in the management of 19,000 ventilator-dependent patients identified in 16 European countries [4]. For example, the prevalence of home ventilation per 100,000 population ranges from 10 in Sweden and 4.1 in the UK to 0.6 in Greece. The proportion in different disease categories also varies widely, e.g. chronic obstructive pulmonary disease (COPD) patients predominate in Italy and Portugal, whereas, in the Netherlands, Denmark, Sweden and Norway, proportionately more individuals with neuromuscular disease are ventilated. This cannot be because the prevalence of these disorders is different. Discrepancies are likely to be due to historical reasons and the fact that centres that have started home ventilator programmes more recently have tended to focus on COPD patients, whereas those which began to provide a service during the 1960s and 1970s have a large cohort of neuromuscular and chest wall (restrictive) patients.

Thus, bearing these anomalies in mind, what is the evidence supporting the use of home NIV in restrictive disorders, progressive neuromuscular disease, paediatric respiratory failure and COPD?

\section{Home ventilation in restrictive ventilatory disorders}

\section{Comparison of ventilatory modes}

Historically, extensive experience has been gained in using all forms of home ventilatory support in restrictive disorders; however, most studies are case series and there have been few randomised controlled trials in patients with chest wall or neuromuscular disease. In early studies, the only ventilatory modes available were NPV and T-IPPV. A long experience (46 yrs) with domiciliary ventilation has recently been published [5]. The authors describe the use of NPV, oral ventilation and NIV in 560 patients with neuromuscular disease treated at the Rancho Los Amigos Medical Center (Downey, CA, USA) during 1949-1995. The vast majority $(n=500)$ had acute poliomyelitis and were recruited at the beginning of the series. Most $(76 \%)$ of these were weaned off NPV within 2 yrs. The report recounts the subsequent course in the polio patients who were still ventilator-dependent after $2 \mathrm{yrs}$, and in a further group who had other forms of neuromuscular and chest wall disease (e.g. Duchenne muscular dystrophy (DMD), myopathy, spinal muscular atrophy, ALS and scoliosis). In total, long-term follow-up data were available for 79 patients. It is notable that 14 of 25 postpolio patients and all non-DMD and myopathy patients treated with NPV ultimately required transfer to tracheostomy ventilation, largely because hypercapnia could not be adequately controlled. Nine of 10 deaths occurred in the patients using NPV, although not all of these could be attributed to respiratory causes. Interestingly, $67 \%$ of patients receiving positive-pressure NIV reported favourable outcomes (improved sense of independence and wellbeing) compared to only $29 \%$ receiving NPV. Problems such as machine discomfort and self-discontinuation of ventilation occurred more than twice as often in negative-pressure users, compared to those receiving NIV or oral ventilation, and, strikingly, hospital admission rates increased a surprising eight-fold after initiation of NPV, but decreased by $36 \%$ in those started on NIV or oral intermittent positive pressure ventilation.
These results should be interpreted with caution as the study has a number of limitations: during the long period of recruitment, equipment evolved, medical teams changed, the patient population shifted from being composed almost entirely of postpolio cases to a heterogeneous mix with small numbers in each category, and patient groups were not matched. These major limitations notwithstanding, the results would suggest that NPV is less efficient than positive-pressure NIV. In addition, the findings imply that a deterioration in lung function and the number of hospital admissions may be reduced in those with nonprogressive pathologies receiving NIV.

T-IPPV is now rarely indicated in restrictive patients other than in situations of extreme ventilator dependency and/or marked bulbar weakness (e.g. in some cases of progressive neuromuscular disease).

Following its introduction in the early 1980s, NIV entered mainstream clinical practice in 1986/1987; therefore, longterm experience is inevitably more limited than for NPV. However, the total database of patients receiving NIV is expanding rapidly and now far exceeds the number of patients using domiciliary negative-pressure techniques. As with NPV, NIV too was first applied in patients with restrictive ventilatory pathology (e.g. scoliosis and neuromuscular disease).

\section{Survival with noninvasive ventilation and its physiological effects}

In a large French multicentric series, the 3-yr probability of continuing domiciliary NIV was $75-80 \%$ for patients with scoliosis and post-tuberculous restrictive disease [6]. Similar results were seen in a single-centre UK cohort which showed a $5-\mathrm{yr}$ actuarial probability of continuing domiciliary NIV of $79 \%(95 \%$ confidence interval (CI) $66-92 \%)$ in scoliotic patients, $100 \%$ in postpolio patients, 94\% $(95 \%$ CI $83-$ $100 \%$ ) in patients with post-tuberculous lung disease and $81 \%$ $(95 \%$ CI $61-100 \%)$ in those with neuromuscular disorders excluding poliomyelitis [7]. This compares to 5-yr probabilities of $43 \%$ in COPD patients and $<20 \%$ in bronchiectasis. In this study, the probability of continuing NIV equates almost entirely with survival since the main reason for discontinuing NIV was death. In the French cohort, $7 \%$ of scoliotic patients discontinued NIV voluntarily and 3\% progressed to tracheostomy ventilation. Almost a third of DMD patients transferred to T-IPPV. Both the UK and French series demonstrate that arterial blood gas tensions during NIV are well-maintained in the long term. Importantly, the French data show that the probability of survival for $5 \mathrm{yrs}$ in scoliosis patients using NIV is significantly better than that using long-term oxygen therapy (LTOT) alone (73 versus $60 \%$ ). As expected, a survival advantage was also seen in posttuberculous lung disease patients (60 versus $53 \%$ ).

\section{Effects of noninvasive ventilation on morbidity and quality of life}

Improvements in morbidity are also consistently seen in NIV users with restrictive disorders. LEGER et al. [6] report significant reductions in the number of days spent as an inpatient for $\geqslant 2$ yrs after initiation of NIV in patients with scoliosis, post-tuberculous lung disease and DMD, implying that worthwhile economic savings can be made.

A UK subgroup who completed the 36-item short-form health survey (SF-36) health status questionnaire gave comparable results to other groups with chronic disorders such as diabetes mellitus and ischaemic heart disease [7]. 
Although physical function was reduced in contrast to agematched population norms, mental health and energy/vitality were similar. Sleep quality is a significant contributor to quality-of-life scores, and, contrary to popular belief, patients using nocturnal NIV rated their sleep quality as average $(67 \%)$ or very good $(27 \%)$, with only $5 \%$ describing sleep quality as poor.

Most recipients found that the main limiting factors of NIV were inconvenience $(19 \%)$, nasal symptoms/mask problems $(9 \%)$, gastric distension (3\%) and noise (3\%) [7]. It can be seen that nasal side-effects and mask problems are less prevalent during long-term NIV than short-term NIV, as use is less intensive and a greater period of time is available for optimising mask fit and minimising side-effects.

\section{Home ventilation in progressive neuromuscular disorders}

Although home ventilation in stable chest wall and neuromuscular disease is likely to have a major influence on mortality and morbidity, in progressive conditions, improvement in quality of life and palliation of symptoms are more relevant. However, it is becoming clearer that NIV in ALS/ MND can prolong survival as well as improve quality of life in some patients, and, in DMD, quite substantial increases in survival can be seen.

\section{Motor neurone diseaselamyotrophic lateral sclerosis}

Respiratory failure, often exacerbated by a chest infection, is the terminal event in many patients with progressive neuromuscular disease. MND (or ALS) is the most prevalent of these disorders; other progressive conditions such as DMD and spinal muscular atrophy are considered below. It is clear that assisted ventilation may extend the life of patients and alter the natural history of these disorders; however, the effects of the intervention on quality of life have not been systematically studied and data are mainly derived from uncontrolled case series. T-IPPV has been used quite extensively in ALS/MND in the USA to circumvent progressive bulbar problems. In practice, selection of patients is often heavily influenced by the degree of insurance cover, extent of independent financial resources and availability of carers. SALAMAND et al. [8] reported a 1-yr survival of $24 \%$ in 24 MND patients receiving home T-IPPV. However, OPPENHEIMER [9] demonstrated improved outcome, with up to $85 \% 1-\mathrm{yr}$ survival. In this series, $>50 \%$ of patients survived for $\geqslant 3$ yrs using home T-IPPV. A French group of patients receiving nasal/oral ventilation or T-IPPV showed transient improvement in pulmonary function, and it was possible to discharge all patients home [10]. Clearly, T-IPPV is the only ventilatory option in patients with severe bulbar disease.

Negative-pressure techniques are unlikely to be helpful in MND as they may exacerbate upper airway dysfunction during sleep and worsen aspiration. NPV has been shown to reduce the symptoms of dyspnoea in several studies, however $[11,12]$.

Theoretically, NIV should be helpful in patients with MND and early respiratory muscle involvement as it may help stabilise the upper airway during sleep. In a controlled study of NIV in ALS/MND, PINTO et al. [13] showed a significant increase in survival in patients with respiratory insufficiency using bilevel ventilatory support compared to a nonventilated control group. However, the quality-of-life tool used in this study showed no improvement. ABOUSSOUAN et al. [14] also found that prognosis was improved in patients who could tolerate NIV. More recently, KLEOPA et al. [15] have shown improved survival and a slower rate of decline in vital capacity (VC) in ALS/MND patients who were started on NIV once VC had fallen below $50 \%$ of the predicted value. Further research has shown an increase in energy and vitality in patients after starting NIV, despite a continuing fall in physical strength [16]. It is crucial to note that, once daytime arterial carbon dioxide tension $\left(\mathrm{Pa}, \mathrm{CO}_{2}\right)$ rises above $6.0 \mathrm{kPa}$, severe ventilatory decompensation is imminent. Bulbar symptoms are not a contraindication to NIV if they are mild or moderate, but may make tolerance of NIV more difficult for the patient [14].

\section{Duchenne muscular dystrophy}

RIDEAU et al. [17] showed that, on average, DMD patients become wheelchair-bound by the age of $10 \mathrm{yrs}$ and $50 \%$ develop a significant scoliosis. Without ventilatory support the mean age at death is $\sim 19$ yrs, with $73 \%$ of deaths occurring as a consequence of hypercapnic respiratory failure. Just under $20 \%$ of patients died during an acute infective exacerbation and $9 \%$ of deaths were attributed to cardiac disease.

The progression of lung function changes in DMD has been divided into three stages: an initial phase, in the first $10 \mathrm{yrs}$, during which forced vital capacity (FVC) increases as predicted; a second phase, during which lung volumes plateau as muscle weakness, and scoliosis if present, becomes manifest; and a final phase, during which FVC initially falls slowly, but may subsequently decline by as much as $250 \mathrm{~mL} \cdot \mathrm{yr}^{-1}$ in the last few years of life [18]. Peak VC is a prognostic factor as a peak $\mathrm{VC}$ of $<1,200 \mathrm{~mL}$ is associated with a mean age at death of 15.3 yrs, whereas values in excess of $1,700 \mathrm{~mL}$ result in survival to $21 \mathrm{yrs}$ [17]. Cardiac involvement takes the form of conduction defects and a dilated or hypertrophic cardiomyopathy. Dilated cardiomyopathy, as evidenced by cardiomegaly and left ventricular dysfunction, is the commonest abnormality. NIGRO et al. [19] found preclinical evidence of cardiac disease in 25\% of DMD patients aged $<6$ yrs and $59 \%$ at age $6-10$ yrs. Clinically apparent cardiac involvement was present in all patients by the age of $18 \mathrm{yrs}$, and $\sim 72 \%$ of these patients were symptomatic. This is important as breathlessness and fatigue due to cardiac failure may be erroneously attributed to respiratory insufficiency.

Before the mid-1980s, the options available for ventilatory support were T-IPPV, mouthpiece ventilation, negativepressure devices, the pneumobelt and the rocking bed. AlEXANDER et al. [20] report a series of patients with latestage DMD who received ventilatory assistance for up to 7 yrs. Patients used a variety of techniques, including mouthpiece IPPV, cuirass, pneumowrap and rocking bed, with the aim of continuing noninvasive methods in the long term and avoiding tracheostomy. Treatment was begun in response to symptomatic hypercapnia and ventilatory support was continued for a mean of 3.4 yrs. Care was delivered in the community and patients were reported to have a meaningful quality of life. By contrast, RIDEAU et al. [17] administered IPPV via a fenestrated tracheostomy in a series of DMD patients following the development of acuteon-chronic respiratory failure or symptoms of nocturnal hypoventilation. All subjects had a moderate-to-severe scoliosis and VC of $<550 \mathrm{~mL}$. A tracheostomy was performed at age 16-23 yrs and none of the patients required daytime ventilatory support, allowing them to complete schooling and carry on with other activities. It is notable that several patients died due to complications related to the tracheostomy. 
Oral intermittent positive pressure ventilation has also been employed effectively in DMD [21], and may be used in addition to other modes as a ventilatory adjunct during the day.

HiLl et al. [22] examined the effects of negative pressure in DMD patients aged $\sim 23$ yrs with a mean VC of $\sim 300 \mathrm{~mL}$. Monitoring of respiration during sleep confirmed that nearly all patients experienced $>5$ episodes $\cdot h^{-1}$ of sleep-disordered breathing accompanied by sleep disruption and desaturation during NPV. These episodes were predominantly obstructive apnoeas or hypopnoeas. Supplemental oxygen was not helpful in alleviating respiratory disturbances, and tended to prolong the duration of such events. The authors found it necessary to use nasal continuous positive airway pressure (CPAP) in two patients and tracheostomy in another as an adjunct to NPV. For all these reasons, NIV is almost certainly the treatment of choice in DMD, although a preliminary study comparing different ventilatory modes in DMD produced inconclusive results [23], and some centres (particularly in France) follow a stepped-care programme. In the UK, patients are initially treated with NIV but progress to T-IPPV if extreme ventilator dependency or severe bulbar problems develop [6].

There has been no controlled study of the use of assisted ventilation in DMD patients with nocturnal and diurnal hypercapnia. However, the long-term effects of NIV have been explored by comparing clinical course and pulmonary function in five hypercapnic patients who received NIV and a control group of five patients who did not receive ventilatory support [24]. Over a 2-yr period, all of the subjects receiving NIV survived, whereas four of five of the control subjects died (mean survival 9.7 months). After 6 months, the mean reduction in VC and maximal voluntary ventilation was significantly greater in the control group. Although these subjects were not randomised to treatment and there was a trend towards an older age, higher $\mathrm{Pa}, \mathrm{CO}_{2}$ and lower tidal volumes in the control group, these results strongly suggest that NIV is of value in prolonging survival in some DMD patients. HILL [25] concluded that the evidence for nocturnal NIV in symptomatic hypercapnic patients with DMD is now so persuasive that research activity should be focused on how rather than whether it works.

Recent work tends to support this concept. Of a UK series of 23 consecutive DMD patients, who presented with hypercapnic ventilatory failure, all were successfully treated using NIV as the sole mode of ventilatory support [26]. Survival at $1 \mathrm{yr}$ was $85 \%$ and at $5 \mathrm{yrs} 73 \%$. Most UK patients needed only nocturnal NIV for the first 3-5 yrs and only subsequently became more ventilator-dependent during the day. Bulbar involvement was a late-stage phenomenon. Quality-of-life scores, measured using the SF-36 questionnaire, were comparable to those obtained in other ventilatordependent patient groups [26].

BACH et al. [27] investigated "life satisfaction" in ventilatordependent DMD patients. Using a postal survey, life satisfaction was assessed in 82 DMD patients and 273 physically intact healthcare professionals (nurses, physicians and therapists). These healthcare professionals were also asked to estimate the quality of life of DMD patients known personally to them. On a scale of 1 (completely dissatisfied) to 7 (completely satisfied), the mean score for DMD patients was 4.9 , and only $12.5 \%$ admitted to dissatisfaction with their lives, despite the fact that 32 patients were receiving roundthe-clock ventilatory support. The mean score for healthcare workers was not markedly different at 5.4, and 9\% expressed dissatisfaction with their lives. Importantly, the healthcare workers consistently underestimated the quality of life of DMD patients. Unfortunately, information on the impact of NIV in DMD does not yet seem to have filtered through to all centres who manage such patients, some of whom do not discuss the option of mechanical ventilation with patients because of a misperception that it results in a poor quality of life [28].

It is becoming clearer that use of a combination of noninvasive inspiratory and expiratory techniques with efficient physiotherapy is at least as effective as invasive tracheostomy ventilation in some patients, provided that there is reasonable preservation of bulbar function. BACH et al. [29], in a retrospective comparison, showed that a noninvasive protocol involving inspiratory and expiratory aids (e.g. cough insufflation/exsufflation) significantly reduced pulmonary morbidity and hospitalisation rates compared to conventional tracheostomy ventilation in DMD patients.

\section{Prophylactic use of noninvasive ventilation in Duchenne muscular dystrophy}

The reports detailed above describe the use of assisted ventilation in individuals with established symptomatic chronic hypoventilation. As an extension of this work, it has been suggested that employment of NIV earlier in the course of the disease, before the development of overt symptoms, may have an even more beneficial effect on the natural history of the condition, by reducing the decline in lung function. A French study addressed this issue and revealed no evidence that the early introduction of NIV in normocapnic DMD patients improves lung function or offers a survival advantage, and indeed that harm may result if ventilation is not adequately monitored [30]. Not surprisingly, this treatment was poorly tolerated. Prophylactic use of NIV in DMD cannot, therefore, be recommended.

\section{Home mechanical ventilation in children}

Reports published during the 1990s reflect the shift from invasive to noninvasive techniques, particularly in children with neuromuscular disease [31, 32]. Although NPV has been used for many years in children, studies comparing different ventilatory techniques in this age range are lacking. Early work suggesting that children aged $<8-10$ yrs were unable to cope with nasal masks has been disproved [33]. TEAGUE and FORTENBERRY [31] demonstrated that bilevel NIV can be used effectively in children with alveolar hypoventilation due to chronic upper airway obstruction, craniofacial disorders and neuromuscular disease. Even children with developmental delay were able to tolerate the mask, and tracheostomy was avoided. Experience has been reported on the use of nocturnal mask ventilation in 40 children with neuromusculoskeletal disease aged 9 months-16 yrs [32]. In these patients, a significant improvement in nocturnal and diurnal arterial blood gas tensions was seen. The majority of children used pressure preset ventilators (e.g. BiPAP; Respironics, Inc., Murrysville, PA, USA; Breas PV401; Breas Medical, Farnham, UK; and Nippy; B\&D Electromedical, Stratford-uponAvon, UK). Approximately half were treated with full-face masks, with the older children preferring nasal masks. Growth velocity improved markedly in some patients. Three children (two with spinal muscular atrophy and one with congenital muscular dystrophy) died over a mean follow-up of 30 months (range 1-105 months). Overall survival in another cohort of children requiring home ventilation was $85 \%$. In most cases, survival is related to the progression of the underlying condition, although it is clear that, in some conditions (e.g. DMD), the natural history of the disorder is 
changed by the addition of ventilatory support. Other than in DMD, there are no firm data as of yet on quality of life in children and infants receiving NIV.

\section{Problems with mask ventilation in children}

There is evidence that the chronic use of tight fitting masks may affect facial growth, resulting in midfacial hypoplasia in some children [34]. This seems more likely if the child starts NIV or CPAP before the age of 8 yrs and has weakness of the facial muscles. Regular evaluation of facial development is advisable. Alternation between face masks, nasal masks and nasal plugs, together with the use of customised masks, may distribute pressure more widely over the facial skeleton in the long term, thereby reducing this problem. Ultimately better mask design and further research on which children are more likely to be affected is required.

\section{Home mechanical ventilation in chronic obstructive pulmonary disease}

T-IPPV has been put to long-term use in COPD patients. In a retrospective French cohort, T-IPPV users showed better initial survival than LTOT recipients, but longer-term mortality was no different [35]. There can be significant mortality and morbidity associated with the tracheostomy itself; therefore, noninvasive modes are preferable. A few small uncontrolled studies have suggested that NPV may have a role to play, but a large controlled trial with patients randomised to either NPV or sham NPV showed no benefit and poor compliance with negative-pressure devices [36].

Unlike the extensive assessment of NIV in acute exacerbations, there have been fewer large-scale randomised controlled trials of domiciliary NIV versus LTOT in stable COPD patients with chronic respiratory failure. After initial case series reports, which demonstrated the feasibility of using home NIV in the 1980s [37, 38], several large cohort studies have been published [7]. In a French series of home NIV recipients, LEGER et al. [6] describe 50 COPD patients, of whom 26 were treated with NIV due to chronic ventilatory failure and 24 received NIV following an acute-on-chronic exacerbation. The mean age at the start of ventilatory support was $63 \mathrm{yrs}$, with a forced expiratory volume in one second of $39 \%$ pred. Of these patients, $88 \%$ received LTOT in addition to NIV. A relatively high number of patients discontinued NIV and $16 \%$ died. The probability of continuing NIV at 3 yrs was $53 \%$. Overall, arterial oxygen tension $\left(\mathrm{Pa}_{\mathrm{a}} \mathrm{O}_{2}\right)$ rose from 6.5 to $7.3 \mathrm{kPa}(49$ to $55 \mathrm{mmHg})(\mathrm{p}=\mathrm{NS})$ and $\mathrm{Pa}, \mathrm{CO}_{2}$ fell from 7.2 to $6.1 \mathrm{kPa}(54$ to $46 \mathrm{mmHg})(\mathrm{p}<0.02)$. The authors implied that better results might have been achieved had NIV been started earlier in the natural history of the disease. In a UK series, comparable survival results were seen, although management differed somewhat in that most patients received NIV alone, without supplemental oxygen, if the mean nocturnal arterial oxygen saturation $\left(\mathrm{Sa}_{2} \mathrm{O}_{2}\right)$ on NIV was $>90 \%$ [7]. The 5-yr probability of continuing NIV in this group was $43 \%$. Six of the 33 patients died due to respiratory failure and five $(15 \%)$ withdrew from therapy because of poor tolerance. From an initial mean \pm SD $P \mathrm{a}, \mathrm{O}_{2}$ of $6.1 \pm 0.8 \mathrm{kPa}(46 \pm 6 \mathrm{mmHg})$ and $P \mathrm{a}, \mathrm{CO}_{2}$ of $8.2 \pm$ $1.7 \mathrm{kPa}(62 \pm 13 \mathrm{mmHg})$, a mean increase in $\mathrm{Pa}, \mathrm{O}_{2}$ of $0.8 \mathrm{kPa}$ $(6 \mathrm{mmHg})$ and decrease in $\mathrm{Pa}, \mathrm{CO}_{2}$ of $0.9 \mathrm{kPa}(7 \mathrm{mmHg})$ was seen at $1 \mathrm{yr}$.
Crossover studies and physiological outcome in chronic obstructive pulmonary disease

Short-term crossover studies comparing NIV to NIV plus LTOT have produced mixed results, almost certainly due to differences in patient selection. In one study, no improvement in diurnal $\mathrm{Pa}, \mathrm{O}_{2}, \mathrm{~Pa}, \mathrm{CO}_{2}$, arterial bicarbonate concentration or $\mathrm{pH}$, or muscle strength was seen after 2 weeks of oxygen therapy, NIV or NIV plus LTOT, although mean $\mathrm{Sa}_{2} \mathrm{O}_{2}$ increased on oxygen alone and NIV plus oxygen, compared to NIV alone [39]. Sleep quality was most impaired in the NIV limb. It is possible, however, that, with this short-term (2-week) protocol, full acclimatisation to NIV did not occur during the period of the study, and the level of pressure support employed was low (mean $12 \mathrm{cmH}_{2} \mathrm{O}$ ). A 3-month study of NIV versus sham NIV was carried out by GAY et al. [40]. Only four of seven patients tolerated bilevel NIV, and no change in arterial blood gas tensions was seen. This is in keeping with results from an earlier crossover study, which demonstrated similar poor compliance and minimal physiological impact [41].

In contrast, two studies have shown an improvement in diurnal $\mathrm{Pa}, \mathrm{O}_{2}$ and $\mathrm{Pa}, \mathrm{CO}_{2}$ in COPD patients using NIV compared to LTOT $[38,42]$. This difference in outcome may be explained by the fact that the only studies showing benefit recruited patients with a greater degree of hyercapnia and aimed to control nocturnal hypercapnia, rather than rest the respiratory muscles.

Taking the above information into account, it is not surprising that a recent meta-analysis of crossover studies lasting $\geqslant 3$ months showed that the mean effect of NIV was small and the $95 \%$ CI of summary results crossed zero (i.e. no significant effect) when gas exchange, pulmonary function, exercise tolerance, sleep efficiency and respiratory muscle strength were considered [43]. These studies were not designed to examine mortality, however.

\section{Quality of life}

As described above, in many studies, only physiological indices before and after NIV were assessed, and clearly these do not tell the whole story of the impact of a treatment on an individual's life. MeEcham Jones et al. [42], using the St George's Respiratory Questionnaire, showed an improvement in total symptoms and disease impact score with NIV compared to oxygen therapy, with which a small deterioration was seen. Using the SF-36 tool, home NIV users were shown to have a comparable health status to groups with other chronic disorders such as diabetes mellitus or heart failure [7], contradicting the popularly held belief that home ventilator users experience a poor quality of life. In a comparison with other groups of ventilator user, however, health status in COPD patients was significantly worse than in those with restrictive disease, and, in some domains, was lower than in those with other progressive disorders such as DMD. Clearly, these comparisons are problematic as age and duration of ventilation vary, and results may be influenced by higher levels of depression and anxiety in the COPD group.

\section{Randomised controlled trials of noninvasive ventilation in chronic obstructive pulmonary disease}

Preliminary results from a longer-term European multicentric randomised trial of NIV versus LTOT plus NIV in stable COPD show no overall advantage of NIV, but suggest that particular subgroups (such as those aged $>65 \mathrm{yrs}$ ) may 
benefit and hospital admissions be reduced, although the frequency of infective exacerbations was not a primary end point when the study was designed [44]. A recent Italian multicentric study showed lower $\mathrm{Pa}, \mathrm{CO}_{2}$, reduced dyspnoea score and improved quality of life in COPD patients using NIV compared to LTOT [45]. Hospital admissions did not differ between the groups but intensive care unit admissions fell among NIV users. A further study suggested a reduction in admissions at 3 months, but this was not maintained in the longer term [46]. It is clear that further definitive randomised trials are needed with exacerbation frequency, hospitalisation and quality of life as key outcome measures, as well as survival. In the meantime, a reasonable conclusion from existing evidence is that domiciliary NIV is unlikely to be effective in most stable COPD patients, particularly if they are normocapnic. However, a subgroup with severe hypercapnia, poor tolerance of LTOT, marked nocturnal hypoventilation and/or recurrent infective exacerbations may benefit.

\section{Compliance with domiciliary noninvasive ventilation in restrictive disorders and chronic obstructive pulmonary disease}

In both the French [6] and UK [7] cohort series, discontinuation rates with NIV were higher in COPD patients than in those with restrictive disorders. LEGER et al. [6] found that $85 \%$ of kyphoscoliotic patients continued NIV in the long term compared to $56 \%$ of COPD patients. In the UK series, only five of $180(3 \%)$ patients discontinued NIV due to poor tolerance and these were all COPD patients. This suggests that the trade-off between symptom relief and nuisance value is inferior in COPD patients. Certainly, the level of physiological improvement in terms of increases in diurnal $\mathrm{Pa}, \mathrm{O}_{2}$ and $\mathrm{Pa}, \mathrm{CO}_{2}$ and survival are less good in obstructive lung disease than in restrictive patients. Higher discontinuation rates in COPD patients are, therefore, explained by lower tolerance and a higher death rate. CRINER et al. [47] found that $65 \%$ (26 of 40 ) of patients continued domiciliary NIV at 6 months and a further $7.5 \%$ had progressed to tracheotomy ventilation. Fifty per cent of these patients had COPD, and so, here too, tolerance was lower in COPD patients.

\section{Mechanisms of action of ventilatory support}

The potential mechanisms of action of ventilatory support include: 1) improved respiratory muscle function; 2) increased chemosensitivity; 3) reduced mechanical load; and 4) improved sleep quality. It is, of course, quite possible that the mechanism of action varies between restrictive and obstructive lung disease patients, and, indeed, may vary to some extent from patient to patient dependent on the underlying pathophysiology

\section{Chest wall and neuromuscular disease}

Improvement in the hypercapnic ventilatory response is probably an important mechanism of action of NIV in chest wall and neuromuscular patients. ANNANE et al. [48] showed that the reduction in $\mathrm{Pa}, \mathrm{CO}_{2}$ that occurs after initiation of NIV in patients with neuromuscular disease and scoliosis correlates with an increase in the slope of the ventilatory response to carbon dioxide $(r=-0.68, p=0.008)$. This study showed no improvement in respiratory muscle strength or lung mechanics. An additional mechanism contributing to increased chemosensitivity to $\mathrm{CO}_{2}$ may be the wash-out of
$\mathrm{CO}_{2}$ stores following correction of overnight hypercapnia. Preliminary data from studies by NicKOL et al. [49] confirm a significant increase in hypercapnic ventilatory response in chest wall and neuromsucular patients, compared to only small increases in COPD patients. In this work, some aspects of respiratory muscle strength improved to a mild degree using invasive measurement via oesophageal balloons.

\section{Chronic obstructive pulmonary disease}

ELLIOTT et al. [50] found a correlation between the fall in $\mathrm{Pa}, \mathrm{CO}_{2}$ and decrease in gas trapping following NIV in COPD patients and suggested that a reduction in lung water may be a factor. This study also showed a reduction in plasma bicarbonate concentration and base excess, and a resetting of the ventilatory response to $\mathrm{Pa}, \mathrm{CO}_{2}$ at a lower level, indicating an improvement in chemosensitivity, as seen in neuromusculoskeletal patients.

SCHONHOFER et al. [51] found a small improvement in sleep quality in COPD patients using NIV, although, interestingly, patients using NIV during the day experienced a comparable improvement in arterial blood gas tensions to those using NIV at night. This result should be contrasted with the finding that, in a short-term study, sleep quality after 2 weeks of NIV was worse than that with oxygen therapy [52].

Recent work examined the effects of temporary discontinuation of NIV in patients previously using this successfully, and may shed light on mechanisms of action [53]. Eleven patients with severe stable ventilatory failure were enrolled, of whom six had COPD. NIV was withdrawn for 6 days or until patients showed significant deterioration in symptoms or arterial blood gas tensions. Five of the 11 patients (three with COPD) required recommencement of NIV before 6 days because of a deterioration in arterial blood gas tensions, which was not necessarily accompanied by an increase in symptoms. In these patients, there were also decreases in tidal volume and inspiratory muscle strength (maximal inspiratory pressure), suggesting a degree of respiratory muscle weakness. Sleep architecture was not assessed in this study. The results suggest that patients discontinuing NIV should be followed closely, as a significant number develop decompensated alveloar hypoventilation.

\section{Selection of patients for home mechanical ventilation and timing of initiation}

Based on the outcome of home ventilation in the various diagnostic groups described above, and a better understanding of its mechanism of action, which patients should be selected and at what point in the natural history of the disease? These issues have been addressed by a recent consensus conference [54]. In summary, this report recommends home NIV in restrictive patients with symptoms (e.g. dyspnoea and morning headache) and either a daytime $\mathrm{Pa}, \mathrm{CO}_{2}$ of $>6.0 \mathrm{kPa}$, nocturnal oximetry measurement of $<88 \%$ for $>5 \mathrm{~min}$ or maximal inspiratory pressure of $<60 \mathrm{cmH}_{2} \mathrm{O}$, or an $\mathrm{FVC}$ of $<50 \%$ pred. The criteria regarding degree of sleep-disordered breathing are not based on published research. In the absence of further evidence, many centres currently initiate NIV when symptomatic nocturnal hypoventilation is present. Waiting until the patient becomes hypercapnic during the day, in some situations, e.g. MND/ALS, may result in uncontrolled decompensation.

The consensus conference suggests that home NIV should be used in stable COPD patients who are symptomatic with either a $\mathrm{Pa}, \mathrm{CO}_{2}$ of $>7.3 \mathrm{kPa}$ or $\mathrm{Pa}, \mathrm{CO}_{2}$ of $6.7-7.2 \mathrm{kPa}$ and 
nocturnal oximetry measurement of $<88 \%$ for $>5$ min on oxygen at $2 \mathrm{~L} \cdot \mathrm{min}^{-1}$, or who have recurrent hypercapnic exacerbations (more than two in a 12-month period). Again, this information is not based on trial results. However, cumulative experience suggests that the COPD patients most likely to benefit are those with marked symptomatic sleepdisordered breathing (especially if there is coexistent obstructive sleep apnoea), those with severe hypercapnia who are intolerant of LTOT and individuals with "revolving door" hypercapnic exacerbations.

\section{Other uses of home ventilation}

\section{Noninvasive ventilation during pulmonary rehabilitation}

The use of NIV during pulmonary rehabilitation programmes is, in theory, an attractive proposition as NIV might enable severe COPD patients to exercise at a higher level and therefore achieve an enhanced training effect. It has been shown that inspiratory pressure support during treadmill exercise reduces dyspnoea and increases the distance walked by reducing the load on the inspiratory muscles [55, 56]. It is possible that progressive dynamic hyperinflation generated during exercise may be successfully offloaded by expiratory positive pressure. A controlled trial in which normocapnic COPD patients were randomised to a pulmonary rehabilitation programme or pulmonary rehabilitation plus home NIV for 8 weeks showed a significant improvement in shuttle walk and Chronic Respiratory Disease Questionnaire score in the group that received NIV [57]. $\mathrm{Pa}_{\mathrm{a}} \mathrm{O}_{2}$ also improved in the NIV limb. However, patients in the pulmonary rehabilitation group without NIV showed no improvement in exercise tolerance, which is atypical for a standard 8-week programme, and mean daily use of NIV was low at $2.1 \mathrm{~h}$. This is an area that warrants further investigation.

\section{Noninvasive ventilation in congestive cardiac failure}

Sleep-disordered breathing is common in congestive cardiac failure, and, if present, worsens prognosis. In patients with Cheyne-Stokes respiration and a combination of periodic breathing and obstructive sleep apnoea, capturing of ventilation overnight (e.g. using the Resmed Autoset CS device; Resmed Ltd, Abingdon, UK) with the aim of increasing $\mathrm{CO}_{2}$ levels in a controlled way is looking as if it may prove an exciting new way of improving cardiac function, symptom load and prognosis. This approach needs to be compared with other treatment options such as oxygen therapy and CPAP.

\section{Risk management in the ventilator-dependent patient}

Discharge planning for the ventilator-dependent patient requires careful attention to risk management. Clearly these plans are more detailed for individuals requiring T-IPPV than in those using nocturnal NIV. Important aspects include a regular maintenance and breakdown service for ventilatory equipment, provision of consumables, competency training for carers, ready access to assessment and respite admissions [58].

\section{Conclusions}

There is conclusive evidence that noninvasive ventilation can prolong survival and improve quality of life in many chest wall and neuromuscular diseases. In other situations, it can palliate symptoms of nocturnal hypoventilation and breathlessness. In stable chronic obstructive pulmonary disease patients, firm evidence is lacking, although specific subgroups may benefit (table 1).

Table 1.-Indications for domiciliary ventilation in respiratory insufficiency

Condition Comments

Chest wall disorders

Scoliosis

Thoracoplasty/previous TB procedures

Fibrothorax

Obesity hypoventilation syndrome

Neuromuscular disease

Congenital

Myopathies

Duchenne muscular dystrophy

Other muscular dystrophies

Spinal muscular atrophy

Hereditary sensory neuropathies, e.g. Charcot-Marie-Tooth disease

Acquired

Old poliomyelitis

Polymyositis

Amyotrophic lateral sclerosis/motor neurone disease

Cervical spinal cord lesion

Neurological disorders

Congenital central hypoventilation syndrome

Brainstem cerebrovascular accident

Obstructive lung disease

Chronic obstructive pulmonary disease

Idiopathic bronchiectasis

Cystic fibrosis
RCTs unlikely: outcome without ventilatory support is death

RCTs unlikely: outcome without ventilatory support is death

RCT: randomised controlled trial; TB: tuberculosis; LTOT: long-term oxygen therapy.

Mixed results; further RCTs versus LTOT required

RCTs versus LTOT required

RCTs versus LTOT required 


\section{References}

1. Adams AB, Shapiro R, Marinii JJ. Changing prevalence of chronically ventilator-assisted individuals in Minnesota: increases, characteristics, and the use of non-invasive ventilation. Respir Care 1998; 43: 635-636.

2. Jardine $\mathrm{E}$, Wallis $\mathrm{C}$. Core guidelines for the discharge home of the child on long term assisted ventilation in the United Kingdom. Thorax 1998; 53: 762-767.

3. www.antadir.com.

4. Lloyd-Owen SJ, Wedzicha JA. Home mechanical ventilation in 16 European countries - a major survey of custom and practice. Eur Respir J 2002; 20: 626s.

5. Baydur A, Layne E, Aral H, et al. Long term non-invasive ventilation in the community for patients with musculoskeletal disorders: a 46 year experience and review. Thorax 2000; 55: 4-11.

6. Leger P, Bedicam JM, Cornette A, et al. Nasal intermittent positive pressure ventilation. Long term follow-up in patients with severe chronic respiratory insufficiency. Chest 1994; 105: 100-105.

7. Simonds AK, Elliott MW. Outcome of domiciliary nasal intermittent positive pressure ventilation in restrictive and obstructive disorders. Thorax 1995; 50: 604-609.

8. Salamand J, Robert D, Leger P, Langevin B, Barraud J. Definitive mechanical ventilation via tracheostomy in endstage amyotrophic lateral sclerosis. 3rd International Conference on Pulmonary Rehabilitation, Denver. 1991; 50.

9. Oppenheimer EA. Amyotrophic lateral sclerosis. Eur Respir Rev 1992; 2: 10, 323-329.

10. Goulon M, Goulon-Goeau C. Sclerose lateral amyotrophique et assistance respiratoire. Rev Neurol (Paris) 1989; 145: 293-298.

11. Sawicka EH, Loh L, Branthwaite MA. Domiciliary ventilatory support; an analysis of outcome. Thorax 1988; 43: 3135.

12. Howard RS, Wiles CM, Loh L. Respiratory complications and their management in motor neuron disease. Brain 1989; 112: $1155-1170$.

13. Pinto AC, Evangelista T, Carvalho M, Alves MA, Sales Luis ML. Respiratory assistance with a non-invasive ventilator (BiPAP) in MND/ALS patients: survival rates in a controlled trial. J Neurol Sci 1995; 129: Suppl., 19-26.

14. Aboussouan LS, Khan SU, Meeker DP, Stelmach K, Mitsumoto $H$. Effect of noninvasive positive-pressure ventilation on survival in amyotrophic lateral sclerosis. Ann Intern Med 1997; 127: 450-453.

15. Kleopa KA, Sherman M, Neal B, Romano GJ, HeimanPatterson T. BiPAP improves survival and rate of pulmonary function decline in patients with ALS. J Neurol Sci 1999; 164: 82-88.

16. Lyall RA, Donaldson N, Fleming $\mathrm{T}$, et al. A prospective study of quality of life in ALS patients treated with noninvasive ventilation. Neurology 2001; 5: 153-156.

17. Rideau Y, Gatin G, Bach J, Gines G. Prolongation of life in Duchenne's muscular dystrophy. Acta Neurol (Napoli) 1983; 5: 118-124.

18. Baydur A, Gilgoff I, Prentice W, Carlson M, Fischer DA. Decline in respiratory function and experience with long term assisted ventilation in advanced Duchenne's muscular dystrophy. Chest 1990; 97: 884-889.

19. Nigro G, Coni LI, Politano L, Bain RJI. The incidence and evolution of cardiomyopthy in Duchenne muscular dystrophy. Int J Cardiol 1990; 26: 271-277.

20. Alexander MA, Johnson EW, Petty J, Stauch D. Mechanical ventilation of patients with late stage Duchenne muscular dystrophy: management in the home. Arch Phys Med Rehabil 1979; 60: 289-292.

21. Bach JR, O'Brien J, Krotenberg R, Alba AS. Management of end stage respiratory failure in Duchenne muscular dystrophy. Muscle Nerve 1987; 10: 177-182.

22. Hill NS, Redline S, Carskadon M, Curran FJ, Millman RP.
Sleep-disordered breathing in patients with Duchenne muscular dystrophy using negative pressure ventilators. Chest 1992; 102: 1656-1662.

23. Raphael J-C, Chevret S, Chastang C, Bouvet F, and the French Multicentric Group. A prospective multicentre study of home mechanical ventilation in Duchenne de Boulogne muscular dystrophy. Eur Respir Rev 1992; 2: 10, 312-316.

24. Vianello A, Bevilacqua M, Salvador V, Cardaioli C, Vincenti E. Long-term nasal intermittent positive pressure ventilation in advanced Duchenne's muscular dystrophy. Chest 1994; 105: 445-448.

25. Hill NS. Noninvasive positive pressure ventilation in neuromuscular disease. Enough is enough! Chest 1994; 105: 337338.

26. Simonds AK, Muntoni F, Heather S, Fielding S. Impact of nasal ventilation on survival in hypercapnic Duchenne muscular dystrophy. Thorax 1998; 53: 949-952.

27. Bach JR, Campagnolo DI, Hoeman S. Life satisfaction of individuals with Duchenne muscular dystrophy using longterm mechanical ventilatory support. Am J Phys Med Rehabil 1991; 70: 129-135.

28. Gibson B. Long-term ventilation for patients with Duchenne muscular dystrophy. Physicians' beliefs and practices. Chest 2001; 119: 940-946.

29. Bach JR, Ishikawa Y, Kim H. Prevention of pulmonary morbidity for patients with Duchenne muscular dystrophy. Chest 1998; 112: 1024-1028.

30. Raphael J-C, Chevret S, Chastang C, Bouvet F. Randomised trial of preventive nasal ventilation in Duchenne muscular dystrophy. Lancet 1994; 343: 1600-1604.

31. Teague WG, Fortenberry JD. Noninvasive ventilatory support in paediatric respiratory failure. Respir Care 1995; 40: 86-96.

32. Simonds AK, Ward S, Heather S, Bush AB, Muntoni F. Outcome of paediatric domiciliary mask ventilation in neuromuscular and skeletal disease. Eur Respir J 2000; 16: 476-481.

33. Heckmatt JZ, Loh L, Dubowitz V. Night-time nasal ventilation in neuromuscular disease. Lancet 1990; 335: 579-582.

34. Li KK, Riley RW, Guilleminault C. An unreported risk in the use of home nasal continuous positive airway pressure and home nasal ventilation in children. Chest 2000; 117: 916918.

35. Muir J-F, and the Cooperative Group. Multicentre study of 259 severe COPD patients with tracheostomy and home mechanical ventilation. Proceedings of the World Congress on Oxygen Therapy and Pulmonary Rehabilitation, Denver. 1987.

36. Shapiro SH, Ernst P, Gray-Donald K, et al. Effect of negative pressure ventilation in severe chronic obstructive pulmonary disease. Lancet 1992; 340: 1425-1429.

37. Marino W. Intermittent volume cycled mechanical ventilation via nasal mask in patients with respiratory failure due to COPD. Chest 1991; 99: 681-684.

38. Elliott MW, Simonds AK, Carroll MP, Wedzicha JA, Branthwaite MA. Domiciliary nocturnal nasal intermittent positive pressure ventilation in hypercapnic respiratory failure due to chronic obstructive lung disease: effects on sleep and quality of life. Thorax 1992; 47: 342-348.

39. Lin M, Chiang HT. The efficacy of early continuous positive airway pressure therapy in patients with acute cardiogenic pulmonary edema. J Formos Med Assoc 1991; 90: 736-743.

40. Gay PC, Hubmayr RD, Stroetz RW. Efficacy of nocturnal nasal ventilation in stable severe chronic obstructive pulmonary disease during a 3 month controlled trial. Mayo Clin Proc 1996; 71: 533-542.

41. Strumpf DA, Millman RP, Carlisle CC, et al. Nocturnal positive-pressure ventilation via nasal mask in patients with severe chronic obstructive pulmonary disease. Am Rev Respir Dis 1991; 144: 1234-1239.

42. Meecham Jones DJ, Paul EA, Jones PW, Wedzicha JA. Nasal pressure support ventilation plus oxygen compared to 
oxygen therapy alone in hypercapnic COPD. Am J Respir Crit Care Med 1995; 152: 538-544.

43. Wijkstra PJ, Lacasse Y, Guyatt GH, Goldstein RS. A metaanalysis of nocturnal non-invasive ventilation (NIPPV) in stable patients with chronic obstructive pulmonary disease. Eur Respir J 2001; 18: 402s.

44. Muir J-F, De la Salmoniere P, Cuvelier A, and the European Group. Survival of severe hypercapnic COPD patients under long-term home mechanical ventilation with NIPPV plus oxygen versus oxygen therapy alone: results of a European multicentre study. Am J Respir Crit Care Med 1999; 159: A295.

45. Clini E, Sturano C, Rossi A, et al. The Italian multicentre study on non-invasive ventilation in chronic obstructive pulmonary disease patients. Eur Respir J 2002; 20: 529538.

46. Casanova C, Celli BR, Tost L, et al. Long-term controlled trial of nocturnal nasal positive pressure ventilation in patients with severe COPD. Chest 2000; 118: 1582-1590.

47. Criner GJ, Brennan K, Travaline JM, Kreimer D. Efficacy and compliance with non-invasive positive pressure ventilation in patients with chronic respiratory failure. Chest 1999; 116: 667-675.

48. Annane D, Quera-Salva MA, Lofaso F, et al. Mechanisms underlying the effects of nocturnal ventilation on daytime blood gases in neuromuscular diseases. Eur Respir J 1999; 13: $157-162$.

49. Nickol AH, Hart N, Heather S, et al. The physiological effect of nocturnal non-invasive ventilation (NIV) in COPD. Eur Respir J 2002; 20: 624s.

50. Elliott MW, Mulvey DA, Moxham J, Green M, Branthwaite MA. Domiciliary nocturnal nasal intermittent positive pressure ventilation in COPD: mechanisms underlying changes in arterial blood gas tensions. Eur Respir $J$ 1991; 4: 1044-1052.

51. Schonhofer B, Geibel M, Sonneborn M, Haidl P, Kohler D. Daytime mechanical ventilation in chronic respiratory insufficiency. Eur Respir J 1997; 10: 2840-2846.

52. Lin C-C. Comparison between nocturnal nasal positive pressure ventilation combined with oxygen therapy and oxygen monotherapy in patients with severe COPD. Am J Respir Crit Care Med 1996; 154: 353-358.

53. Karakurt S, Fanfulla F, Nava S. Is it safe for patients with chronic hypercapnic respiratory failure undergoing home noninvasive ventilation to discontinue ventilation briefly? Chest 2001; 119: 1379-1386.

54. Consensus Conference. Clinical indications for noninvasive positive pressure ventilation in chronic respiratory failure due to restrictive lung disease, COPD, and nocturnal hypoventilation - a Consensus Conference report. Chest 1999; 116: 521-534.

55. Polkey MI, Kyroussis D, Mills GH, et al. Inspiratory pressure support reduces slowing of inspiratory muscle relaxation rate during exhaustive treadmill walking in severe COPD. Am J Respir Crit Care Med 1996; 154: 1146-1150.

56. Kyroussis D, Polkey MI, Hamnegard C-H, Mills GH, Green M, Moxham J. Respiratory muscle activity in patients with COPD walking to exhaustion with and without pressure support. Eur Respir J 2000; 15: 649-655.

57. Garrod R, Mikelsons C, Paul EA, Wedzicha JA. Randomized controlled trial of domiciliary non-invasive positive pressure ventilation and physical training in severe chronic obstructive pulmonary disease. Am J Respir Crit Care Med 2000; 162: 1335-1341.

58. Simonds AK. Discharging the ventilator dependent patient Eur Respir Mon 2001; 16: 137-146. 